\title{
EL PENSAMIENTO ECLESIAL DE LA REVISTA «VIDA NUEVA» EN EL POSCONCILIO
}

Fecha de recepción: 29 de diciembre de 2019

Fecha de aceptación: 16 de mayo de 2020

RESUMEN: Al igual que la Iglesia tras el Concilio Vaticano II, Vida Nueva experimenta un proceso de profunda transformación: en el periodo posconciliar, la revista comienza un camino de renovación especializándose en un periodismo de información religiosa. Este estudio muestra la acogida del Concilio por Vida Nueva y sus propuestas en materia eclesial a través de un análisis de contenido de los editoriales del semanario de 1968 a 1975. Los resultados indican que el mensaje conciliar influye en la revista, debido a la manera de entender y analizar los acontecimientos de la Iglesia de índole nacional e internacional. El semanario tiene particularmente presente la labor de Pablo VI y de los obispos, por medio de las actividades y documentos publicados por el papa, y el trabajo de las diócesis y conferencias episcopales. Asimismo, para la revista, la apuesta por la renovación implica el compromiso de los presbíteros, los religiosos y los laicos. Igualmente, reflexiona sobre temas debatidos en el seno de la Iglesia como el celibato sacerdotal, los ministerios femeninos, la responsabilidad de los laicos y la secularización. Además, para llevar a la práctica las reformas, Vida Nueva apuesta por la promoción de las nuevas corrientes teológicas, la actualización del lenguaje, la renovación de los métodos pastorales, la reforma de la liturgia, el impulso de la evangelización, la formación de los creyentes, el fomento de la doctrina social, el ecumenismo y el diálogo interreligioso.

PALABRAS CLAVE: posconcilio; Concilio Vaticano II; línea editorial; comunicación religiosa.

*Universidad Pontificia Comillas: jscamacho@comillas.edu;

ORCID: https://orcid.org/0000-0002-9087-6959 


\section{The Ecclesial Thinking of Vida Nueva Magazine in the Postcouncil Period}

ABSTRACT: As the Church after the Second Vatican Council, Vida Nueva was undergoing a process of profound transformation: in the postconciliar period, the magazine is beginning a journey of renewal by specializing in religious news journalism. This study shows the acceptance of the Council by the magazine and its proposals in ecclesial issues through the results of the analysis of the editorial contents of Vida Nueva from 1968 to 1975 . The results reveal that the Conciliar message influences the journal, due to the way it understands and analyses national and international Church events. The publication reflects on the work of Paul VI and the bishops, through the activities and documents published by the Pope, and the work of the dioceses and episcopal conferences. Furthermore, for the magazine, the commitment to renewal includes the involvement of priests, religious and lay people. For this reason, it reflects on themes discussed within the Church such as priestly celibacy, women's ministries, the responsibility of the laity and secularization. In addition, in order to put the reforms into practice, Vida Nueva is committed to the promotion of new theological currents, the updating of language, the renewal of pastoral methods, the reform of the liturgy, the encouragement of evangelization, the formation of believers, the promotion of social doctrine, the ecumenism and the interfaith dialogue.

KEY WORDS: postcouncil period; Vatican II; editorial line; religious communication.

\section{INTRODUCCIÓN}

Hace cincuenta años, la Iglesia católica se encontraba en un proceso de profunda renovación. El mensaje de los documentos publicados por el Concilio Vaticano II fue interpretado en los años posteriores a su celebración ${ }^{1}$. En este sentido, en relación con la colegialidad episcopal, las respectivas diócesis y conferencias episcopales tuvieron una labor destacada $^{2}$. Hoy, el Concilio Vaticano II sigue abriendo nuevos horizontes al futuro de la comunidad eclesial ${ }^{3}$. De hecho, en la actualidad, los paralelismos existentes entre el camino de renovación del papa Francisco y el

${ }^{1}$ Cf. Santiago Madrigal. "La recepción del Concilio Vaticano II". Revista Iberoamericana de Teología 13 (2011): 60.

2 Cf. José de Jesús Legorreta Zepeda. "Las conferencias episcopales en el debate teológico postconciliar". Revista Iberoamericana de Teología 13 (2011): 31.

3 Cf. Santiago Madrigal. "El Concilio Vaticano II: remembranza y actualización". Revista Teología 117 (2015): 131-163. 
pontificado de Pablo VI abren nuevas líneas de investigación ${ }^{4}$. Por ello, un estudio sobre la recepción del Concilio Vaticano II sigue teniendo un significado relevante en la Iglesia del siglo XXI.

La prensa religiosa jugó un papel fundamental en la aplicación del Concilio. En los años preconciliares, empezaron a emerger revistas de carácter divulgativo ${ }^{5}$, predominando principalmente las hojas parroquiales y las publicaciones de piedad popular ${ }^{6}$. Específicamente, Ecclesia y Vida Nueva son las dos únicas revistas que intentan cubrir toda la información eclesial religiosa del posconcilio. Sin embargo, mientras que la primera publicación tiene como principal objetivo la divulgación de documentos pontificios y episcopales, la segunda es un semanario independiente que hace un tratamiento de la información a través de distintos géneros periodísticos como la noticia, la crónica, el reportaje, la entrevista, el editorial y la opinión ${ }^{7}$.

Tras los años del Concilio, el semanario social y religioso Vida Nueva comienza a experimentar un profundo proceso de renovación, especializándose en la información religiosa. De esta tarea se ocupa el presbítero, periodista y escritor José Luis Martín Descalzo, quien dirige la revista durante más de siete años ${ }^{8}$. Esta etapa de Vida Nueva no solo está marcada por un tiempo de transformación, sino también de crisis eclesial, ya que ciertos sectores del catolicismo se muestran resistentes a las novedades del Concilio 9 . Y si al aggiornamento se le suma la revolución cultural de 1968 y la crisis social en la última fase del franquismo ${ }^{10}$, se obtiene como resultado un momento crucial para la misión de la Iglesia y, particularmente, para el mundo de la información religiosa.

${ }^{4}$ Cf. Mark Joseph Zammit. “'La Iglesia se inclina hacia el hombre y hacia el mundo': el puesto central del diálogo de Pablo VI en el Concilio Vaticano II”. Estudios Eclesiásticos 370 (2019): 550-551.

5 Cf. Carlos Barrera. "Revistas católicas y conflictos con el poder político en el tardofranquismo". Anuario de la Historia de la Iglesia 10 (2001): 122-142.

6 Cf. Ángel Orbegozo. La Prensa de la Iglesia en España. Madrid: Oficina General de Información y Estadística de la Iglesia en España, 1957, 43-45.

7 Cf. Bernardino Martínez Hernando. "Historia de Vida Nueva. Los últimos 30 años del catolicismo español a través de una revista". Tesina de fin de carrera en la Escuela Oficial de Periodismo, Madrid, 1973, 7-8.

8 Cf. Editorial. “José Luis Martín Descalzo sucede a José María Pérez Lozano en la dirección de Vida Nueva”. Vida Nueva 650 (2 de noviembre de 1968): 5.

9 Cf. Olegario González de Cardedal. La Teología en España (1959-2009). Memoria y prospectiva. Madrid: Encuentro, 2010, 247-248.

10 Cf. Javier Tusell. La España de Franco. Madrid: Historia 16, 1989, 199-202. 
Este artículo tiene como objetivo mostrar la manera de entender la Iglesia y el impacto del Concilio Vaticano II en la revista Vida Nueva a través de sus editoriales. Los objetivos específicos de investigación se preguntan acerca de cómo aprecia la revista las novedades del Concilio Vaticano II; qué concepto tiene el semanario de la jerarquía eclesiástica, el clero, la vida religiosa y los laicos; cómo valora las nuevas corrientes teológicas; qué papel desempeña para la revista el Concilio Vaticano II en la renovación de la Iglesia; cómo entiende la misión de la Iglesia en un mundo cada vez más secularizado; cuál es el tratamiento de la doctrina social de la Iglesia y la implicación de los cristianos en los asuntos temporales; y qué importancia tiene el ecumenismo y el diálogo interreligioso.

Para conocer la temática más destacada del semanario y los temas a través de los cuales intentó influir sobre sus lectores ${ }^{11}$, se han retomado los resultados de un análisis de contenido que examina la repercusión del Concilio en la Iglesia y los cambios sociales, políticos, económicos y culturales a través de la línea editorial de Vida Nueva ${ }^{12}$. Además, en este estudio han estado presentes otros trabajos sobre la revista que han servido para sentar las bases de la investigación y poder delimitarla en la línea editorial del semanario ${ }^{13}$.

${ }^{11}$ Cf. Maxwell E. McCombs, y Donald L. Shaw. "The Agenda-Setting Function of Mass Media”. The Public Opinion Quarterly 36, n. ${ }^{\circ} 2$ (1972): 176-187.

12 Cf. Jesús Sánchez-Camacho. "El impacto del Concilio Vaticano II y la transformación social de la España tardofranquista en la línea editorial de Vida Nueva (19681975)". Tesis doctoral, Universidad Pontificia de Salamanca, 2018.

13 Cf. Martínez Hernando. "Historia de Vida"; Bernardino Martínez Hernando. "La personalidad de Vida Nueva. Análisis hemerográfico". Tesina de Licenciatura, Facultad de Ciencias de la Información, Universidad Complutense de Madrid, 1982; José Francisco Serrano Oceja. "La obra publicística de Lamberto de Echeverría y Martínez de Marigorta: Incunable y PPC en la renovación del catolicismo español”. Tesis doctoral, Universidad Pontificia de Salamanca, 1999; Yolanda Cagigas Ocejo. La revista Vida Nueva (1967-1976): un proyecto de renovación en tiempos de crisis. Pamplona: EUNSA, 2007; Ninfa Watt. "Vida Nueva. Medio Siglo de una revista (1985-2008)", Tesis doctoral, Universidad Pontificia de Salamanca, 2008; Ninfa Watt, Pablo Rey, y José David Urchaga-Litago. Vida Nueva en la Transición. Iglesia y sociedad españolas en la línea editorial del semanario de PPC. Barcelona: Ediciones STJ, 2010. El trabajo de Yolanda Cagigas Ocejo es el que mantiene un vínculo más directo con este estudio debido al periodo trabajado. Sin embargo, la metodología y las fuentes primarias utilizadas son distintas. Desde una perspectiva histórica y a través de piezas informativas de distintos géneros periodísticos como la noticia, la crónica, el reportaje, el editorial o la opinión, la obra de Yolanda Cagigas Ocejo realiza un recorrido por las principales efemérides sociales y eclesiales de los años del posconcilio. 
Las fuentes primarias son los editoriales del 2 de noviembre de 1968 (número 650) al 3 de enero de 1976 (número 1011): un total de 360 textos, codificados a través de categorías de investigación ${ }^{14}$ que han servido para conocer cuantitativamente la presencia de los temas eclesiales ${ }^{15}$. Posteriormente, a la luz del contenido de los editoriales, se han interpretado los datos través del análisis cualitativo ${ }^{16}$. De los 360 editoriales analizados, en este estudio se han citado 63, cuyos contenidos constituyen una muestra representativa del enfoque eclesial de la línea editorial de Vida Nueva en el posconcilio.

Para realizar esta investigación, se ha elegido el editorial como el género periodístico más pertinente para el análisis del pensamiento eclesial de Vida Nueva. Además de ser el género más leído por los lectores de Vida Nueva en el posconcilio ${ }^{17}$, el editorial es el encargado de exponer los hechos, encuadrar los antecedentes, pronosticar el futuro y enunciar juicios ${ }^{18}$. El área de esta investigación se ubica en el campo de la comunicación mediática y, por tanto, se trata de un estudio analítico ${ }^{19}$. Sin embargo, ya que las conclusiones del trabajo aportan conocimiento sobre la

${ }^{14}$ Cf. Roger Wimmer y Joseph Dominick. La investigación científica de los medios de comunicación. Barcelona: Bosch Casa Editorial S. A., 1996, 181-183.

${ }^{15}$ Las siguientes categorías de estudio han servido para codificar y analizar los 360 editoriales: Iglesia Universal, Iglesia en España, Magisterio, Santa Sede, Obispos, Clero, Seminarios, Celibato sacerdotal, Ministerios, Vida religiosa, Sentido de pertenencia, Organización, Preconcilio, Concilio Vaticano II, Doctrina social, Corrientes eclesiales, Signos de los tiempos, Evangelización, Formación, Movilización, Tiempos litúrgicos, Renovación, Renovación: lenguajes, Renovación: métodos, Renovación: liturgia/sacramentos, Renovación: catequesis, Riquezas/patrimonio, Ecumenismo, Diálogo interreligioso, Teología, Ateísmo y secularización, Fe y espiritualidad, Devoción mariana.

${ }^{16}$ Cf. María del Carmen García Galera y María Rosa Berganza Conde. "El método científico aplicado a la investigación en Comunicación Mediática". En Investigar en Comunicación. Guía práctica de métodos y técnicas de investigación social en Comunicación, dirigido por María Rosa Berganza Conde y José Antonio Ruiz San Román, 19-42. Madrid: McGraw-Hill, 2005.

17 Cf. José Luis Martín Descalzo, y Bernardino Martínez Hernando. “3.600 lectores de Vida Nueva juzgan su revista”. Vida Nueva 1009 (20 de diciembre de 1975): 22-31.

18 Cf. Luisa Santamaría. El comentario periodístico. Los géneros persuasivos. Madrid: Paraninfo, 1990, 56.

19 Cf. María Rosa Berganza Conde. "La aplicación de métodos estadísticos a la investigación en medios de comunicación". En Investigar en Comunicación. Guía práctica de métodos y técnicas de investigación social en Comunicación, dirigido por María Rosa Berganza Conde y José Antonio Ruiz San Román, 113-147. Madrid: McGraw-Hill, 2005. 
acogida del Concilio en la prensa religiosa, esta investigación desea contribuir a la reflexión teológica sobre la orientación pastoral del Concilio y la dimensión social de la evangelización de la Iglesia.

En primer lugar, se expone la fundación y el proceso de renovación de la revista Vida Nueva. Posteriormente, se observa cómo los editoriales cubren las noticias más destacadas sobre los acontecimientos de la Iglesia, del papa y de los obispos. Después, se muestra el tratamiento de la información editorial en el resto de ministerios eclesiales - presbiterado, vida religiosa y laicado-. Asimismo, se presenta la renovación del Concilio y las propuestas de la revista en materia teológica y pastoral. Igualmente, se expone, según el semanario, el camino de la evangelización en una época marcada por la secularización. Igualmente, se observa las implicaciones que para la revista tiene la doctrina social de la Iglesia en la vida del creyente. Y, por último, se presenta la visión de Vida Nueva sobre las relaciones entre cristianos de diferentes confesiones.

\section{NACIMIENTO Y AGGIORNAMENTO DE VIDA NUEVA}

La Navidad de 1954 fue especial, sobre todo, para un grupo de amigos reunidos cerca del Tajo en Toledo ${ }^{20}$. Allí no solo nacen los Folletos de PPC, sino también "un determinado modo de ver la Iglesia y en un concreto estilo de servirla» ${ }^{21}$. Un año más tarde, mientras Lamberto de Echeverría planeaba una publicación destinada a seglares, la revista Incunable pone a disposición de PPC un suplemento llamado Pax. Esta publicación adopta el nombre de Vida Nueva el 1 de enero de $1958^{22}$. La nueva revista, dirigida por José María Pérez Lozano, tiene como fin ser una publicación familiar de largo alcance en el ámbito católico ${ }^{23}$.

A comienzos de diciembre de 1965, la Iglesia experimentaba un profundo aggiornamento. El Concilio estaba a punto de finalizar y serían

${ }^{20}$ Lamberto de Echeverría, director de Incunable, Antonio Montero, subdirector de Ecclesia, José María Javierre, asesor religioso de Ya, Ángel Orbegozo, director de Signo, José María Pérez Lozano, redactor-jefe de Incunable y Senda, y Francisco Izquierdo, asesor artístico. Cf. Watt, "Vida Nueva. Medio", 98-99.

${ }^{21}$ José Luis Martín Descalzo. "Qué ha sido, qué es, qué quiere se Vida Nueva”. Vida Nueva 1000 (11/18 de octubre de 1975): 7.

22 Cf. Watt, "Vida Nueva. Medio", 159-188, 231-241.

23 Cf. Ibid., 188-191. 
publicados sus últimos documentos. Esa fecha no solo es relevante para los lectores de Vida Nueva por la magnitud del acontecimiento eclesial, sino también porque la revista lanza un innovador y moderno diseño con impresión offset, con nuevas secciones y contenidos. Sin embargo, esta renovación no mitiga la caída del número de suscripciones que el semanario venía registrando desde $1963^{24}$.

Entretanto, las noticias provenientes de Roma, tras la celebración del Concilio y su recepción en España, salpicaban las páginas de las publicaciones generalistas. Por ello, Vida Nueva considera que, en el mundo de la información religiosa "se hacía imprescindible» una revista que recompusiera "el rompecabezas de lo que fragmentariamente les servía la prensa diaria», con el fin de seguir "día a día los hilos de la noticia, en todo su hervor y confusión ${ }^{25}$. En consecuencia, en diciembre de 1967, la revista da un paso hacia la especialización en el ámbito religioso, inaugurando un nuevo formato offset a cuatro colores en la cubierta, aumentando a 36 el número de páginas, renovando sus secciones, precisando el uso de los distintos géneros periodísticos, dando voz a los lectores a través de sus cartas y haciendo manifiesta su línea editorial ${ }^{26}$.

Por tanto, Vida Nueva se distancia del tradicional formato de publicación de familia y se centra en la información religiosa. Esa renovación no cambiaría la brújula de la revista, que desde el momento de su nacimiento estuvo dirigida al «servicio de lo que la Iglesia fuera necesitando sobre la marcha ${ }^{27}$. Pero eso no significa para el director de Vida Nueva ponerse al servicio de la «Jerarquía» o de ciertos «intereses eclesiásticos», sino a disposición de la «realización del evangelio y, por tanto, de la verdad» ${ }^{28}$. Esto no quiere decir que la revista fuera una publicación exclusivamente de carácter eclesial, a pesar de que estuviera inscrita como publicación «de información general y religiosa». Vida Nueva no desea ser meramente de "índole teológica: nunca entendimos a la Iglesia como un "ghetto" separable del resto de los problemas humanos; ya mucho antes del Concilio entendíamos a la Iglesia en el mundo, para el mundo» ${ }^{29}$. En efecto, su adhesión al Concilio Vaticano II determina su visión sobre la misión

${ }^{24}$ Cf. Martínez Hernando. "La personalidad de", 42-43.

25 Martín Descalzo. "Qué ha sido", 5.

26 Vida Nueva 602 (2 de diciembre de 1967).

27 Martín Descalzo. "Qué ha sido", 5.

28 Íd.

29 Íd. 
de la Iglesia en el mundo, concibiendo la realidad espiritual y temporal como dos dimensiones complementarias del mensaje cristiano ${ }^{30}$.

Pensando «a la Iglesia en el mundo», la revista se va especializando paulatinamente en un periodismo de información religiosa novedoso para España, debido a «una concreta necesidad histórica»:

«Los años del Concilio sacaron a la Iglesia al primer plano de las informaciones. La vida de la comunidad católica se convirtió en noticia. Los diarios, que antaño arrinconaban su sección religiosa, que no era, en definitiva, sino una sección de "cultos", con sus listas de novenas y el comentario evangélico del domingo, de pronto hicieron saltar a los obispos, los curas y las organizaciones apostólicas a sus primeras planas. No pocas veces como objetos de polémica, muchas para utilizar sus opiniones al servicio de banderas políticas de uno u otro color, casi siempre para ofrecer retazos de verdad sobre la Iglesia que contribuían más a la confusión que a la iluminación sobre su verdadera misión en el mundo y sobre el sentido de sus acciones» ${ }^{31}$.

La incorporación de José Luis Martín Descalzo, como director de Vida Nueva, es un factor decisivo que conduce a la revista por el camino del éxito de la información católica. El 2 de noviembre de 1968, un presbítero, escritor natural de Madridejos (Toledo) y periodista corresponsal en el Concilio para La Gaceta del Norte, toma el pulso a la actualidad religiosa y social en Vida Nueva ${ }^{32}$. Pero Martín Descalzo no acomete el proyecto de manera solitaria, ya que se apoya en un equipo de redactores y colaboradores que cada semana presenta la actualidad religiosa y social ${ }^{33}$.

30 Tema presente en documentos conciliares como la Constitución Pastoral Gaudium et spes sobre la Iglesia en el mundo actual y el Decreto Apostolicam Actuositatem sobre el apostolado de laicos (cf. GS 36, 38, 41, 43, 76; AA 4-7).

31 Martín Descalzo. "Qué ha sido”, 5.

32 José Luis Martín Descalzo nace el 27 de agosto de 1930. Tras vivir en Astorga, ingresa en el Seminario de Valladolid y se traslada a Roma para estudiar Teología e Historia de la Iglesia. Posteriormente, estudia en la Escuela Oficial de Periodismo y, como profesional del mundo de la información, empieza a destacar a raíz de sus crónicas del Concilio Vaticano II. Tras trabajar en El Norte de Castilla, Ya, La Gaceta del Norte y $A B C$, PPC le encomienda la tarea de sustituir a José María Pérez Lozano. Cf. Watt. "Vida Nueva. Medio", 267-270.

${ }_{33}$ A través de la mancheta de Vida Nueva del número 1010 podemos observar el equipo de trabajo del semanario: "Director: José Luis Martín Descalzo. Redactor jefe: Bernardino M. Hernando. Redactores, colaboradores y equipo artístico: Juan Abarca, Manuel Alcalá, Enrique Arenós (Quique), Juan Barberán, María Luisa Bouvard, José 
Además, una de las principales novedades del semanario en el nuevo camino comenzado a finales de 1967 es la inserción del género editorial, fuente primaria de este estudio. La mayoría de estos textos son escritos por el director de la revista, José Luis Martín Descalzo ${ }^{34}$.

En 1974, el equipo de Vida Nueva consigue que el semanario alcance una tirada nunca obtenida hasta entonces, superando las 27.000 suscripciones $^{35}$. Al inicio de la Transición española, habiendo cumplido el plazo de los siete años propuestos por PPC, José Luis Martín Descalzo se despide de sus lectores, dando el relevo a Bernardino Martínez Hernando ${ }^{36}$.

María Burgos, Pedro Darnell, Lamberto de Echeverría, Tomás Fernández, Pedro G. Candanedo, Javier García Montero, Francisco Izquierdo, José Jiménez Lozano, Pedro M. Lamet, José María de Llanos, Martín Prieto, Miguel Mateos, Joaquín Luis Ortega, Antonio Pelayo, Saturnino Rodríguez, Luis S. Rufo, Mary Salas, Mary G. Santa Eulalia, Armando Vázquez, María Paz Rodríguez". Vida Nueva 1010 (27 de diciembre de 1975): 3. En aquella mancheta no están presentes otros redactores y colaboradores que, de 1968 a 1975, también forman parte de Vida Nueva: Ángel Orbegozo, Manuel Gómez Ortiz, Manuel de Unciti — redactor jefe anterior a Bernardino M. Hernando-, Antonio Montero, Antonio Alférez, Eduardo Cierco, Ricardo Sanchís, Emilio Rey, Antonio González Hernández, Joel Alegría, Sushila Nadu, Juan Luis Pintos, Javier Portocarredo, J. A. Quiroga, Juan Parejo, Teófilo Cabestrero y M. Begoña Isusi.

${ }^{34}$ Según Antonio Pelayo, el director de Vida Nueva «escribía los editoriales todos los lunes por la mañana, habiéndolo meditado previamente durante todo el fin de semana». Aquel redactor, reconociendo su juventud y su falta de experiencia en aquellos momentos, recuerda las reuniones semanales con José Luis Martín Descalzo, Bernardino Martínez Hernando y Joaquín Luis Ortega, para debatir el enfoque de los editoriales. Cf. Antonio Pelayo. Comunicación con el autor, 7 de abril de 2014. Además, Bernardino Martínez Hernando apunta que, como algunos lunes el director de la revista no se encontraba en la redacción, otros editoriales fueron escritos por Manuel Unciti y por él mismo. Cf. Bernardino Martínez Hernando. Comunicación con el autor, 17 de octubre de 2017. Asimismo, Joaquín Luis Ortega también recuerda con emoción los momentos en los que contribuyó en la elaboración de los editoriales del semanario. Cf. Joaquín Luis Ortega, comunicación con el autor, 19 de noviembre de 2017.

35 Cf. Martínez Hernando. "La personalidad de", 6, 43.

36 Cf. Editorial. "Año nuevo, director nuevo". Vida Nueva 1011 (3 de enero de 1976): 5 . 


\section{EL TRATAMIENTO DE LOS ACONTECIMIENTOS ECLESIALES Y LA JERARQUÍA DE LA IGLESIA}

El desafío de la renovación de la revista implica un amplio tratamiento de la información religiosa, dando voz a los acontecimientos eclesiales más destacados de índole nacional e internacional. En este sentido, de los 360 analizados, los temas relacionados con la Iglesia están presentes en 333 editoriales de la revista (92,5\%). Vida Nueva es consciente de la importancia de la constitución jerárquica de la Iglesia en el Concilio ${ }^{37}$ y, como muestra la tabla 1, cubre las noticias vinculadas a la jerarquía de la Iglesia y los asuntos eclesiales de rango nacional e internacional en sus editoriales:

TABLA 1

\begin{tabular}{|l|c|c|}
\hline \multicolumn{1}{|c|}{ Categorías } & $\mathbf{N}^{\mathbf{}}$ & Porcentaje \\
\hline Obispos & 182 & 50,6 \\
\hline Iglesia en España & 149 & 41,4 \\
\hline Santa Sede & 133 & 36,9 \\
\hline Iglesia Universal & 125 & 34,7 \\
\hline
\end{tabular}

Las noticias de la Iglesia en España $(41,4 \%)$ e Iglesia Universal $(34,7 \%)$, tratadas en los editoriales de Vida Nueva, revelan tanto el espíritu de catolicidad de la revista como una particular preocupación por la Iglesia local. En este sentido, se vislumbra la orientación del semanario hacia la colegialidad, a través del tratamiento de los sínodos, las decisiones episcopales y los textos publicados por las conferencias episcopales ${ }^{38}$. La línea editorial del semanario define a los miembros de la CEE (Conferencia Episcopal Española) durante los tres trienios (1966, 1969 y 1971) $)^{39}$.

37 Cf. LG 17-29.

38 En el Concilio, la colegialidad fue promovida por la Constitución Dogmática Lumen Gentium (cf. LG 22-23, 28), y el establecimiento de las conferencias episcopales se estableció en el Decreto Christus Dominus sobre el ministerio pastoral de los Obispos (cf. CD 37-38).

${ }^{39}$ Fernando Quiroga Palacios, cardenal arzobispo de Santiago de Compostela, fue elegido presidente de la CEE en 1966; Casimiro Morcillo González, arzobispo de Madrid Alcalá, en 1969; y Vicente Enrique y Tarancón, cardenal arzobispo de Madrid-Alcalá, en 1971. Cf. Pablo Martín de Santa Olalla, y José Francisco Serrano 
Para Vida Nueva, en el primer trienio, los obispos estaban «unidos para nada»; en el segundo, a pesar de darse «una evolución visible y pastoral», estaban "desunidos por algo»; y en el tercero, podrían haber estado «unidos para algo» - pero hubo «un desajuste de ritmo entre la Plenaria y la Permanente [...], lo que la Plenaria proyectaba o tejía, era destejido o rebajado con frecuencia por los órganos directivos»— ${ }^{40}$. Principalmente, el semanario considera un avance fundamental la publicación de La Iglesia y los pobres ${ }^{41}$ y La Iglesia ante el momento actual: petición de libertad para detenidos políticos en $1975^{42}$.

Un ejemplo del interés de la revista por la participación de toda la comunidad eclesial es la celebración de la Asamblea Conjunta de obispos y sacerdotes en 1971, que intentó adaptar el Concilio a la realidad social, económica, cultural, política y religiosa de España ${ }^{43}$. La revista analiza esta Asamblea, desmintiendo, en primer lugar, las noticias que tildaban esta reunión de "convulsa, agitada, política, ácida, mundanizada». De hecho, Vida Nueva la cataloga como una "asamblea serena", llena de "diversidad de mentalidades y corrientes» ${ }^{44}$. No obstante, el semanario echa de menos procedimientos más ágiles y participativos que impliquen a religiosos y laicos ${ }^{45}$.

Al tomar el pulso de la vida de la Iglesia, la revista presta una atención significativa en sus editoriales a las noticias relacionadas con la Santa Sede $(36,9 \%)$. En concreto, su aprecio por el Pontífice no solo lo demuestra con el aplauso; también con la crítica. Vida Nueva expresa la manera de

Oceja. 50 años de la Conferencia Episcopal Española. Madrid: Encuentro, 2016, 19, 20, 30, 35-36, 45-46, 65-66, 80.

${ }^{40}$ Editorial. "La cuarta singladura de la Conferencia episcopal española". Vida Nueva 971 (1 de marzo de 1975): 5-7.

${ }^{41}$ Cf. Conferencia Episcopal Española. "La Iglesia y los pobres". 11 de julio de 1970. Consultado el 27 de diciembre de 2019. http://www.conferenciaepiscopal.nom. es/archivodoc/jsp/system/win_main.jsp

${ }^{42}$ Cf. Conferencia Episcopal Española. "La Iglesia ante el momento actual: petición de libertad para detenidos políticos". 19 de diciembre de 1975. Consultado el 27 de diciembre de 2020. http://www.conferenciaepiscopal.nom.es/archivodoc/jsp/ system/win_main.jsp

43 Cf. Juan María Laboa. Pablo VI, España y el Concilio Vaticano II. Madrid: PPC, 2017, 191-215.

${ }^{44}$ Editorial. "Un paso histórico en la vida de nuestra Iglesia”. Vida Nueva 799/800 (25 de septiembre/2 de octubre de 1971): 3-5.

45 Cf. Íd. 
querer a Pablo VI: se trata de una «forma moderna — tan hermosa, pero tan incómoda- de amar criticando» ${ }^{46}$. El semanario evalúa al Pontífice, acentuando su trabajo en la defensa los derechos humanos, la justicia social, la paz, su actitud cercana, su orientación renovadora, los documentos publicados, sus declaraciones, su perfil dialogante y moderado, los viajes realizados y su apoyo a la autonomía del orden temporal. En efecto, la revista se muestra visceralmente montiniana y reconoce que lo fue «antes de su elección al pontificado, en su elección, después de ella » ${ }^{47}$. Pero eso no implica que, en el setenta y cinco cumpleaños de Pablo VI el semanario llegue a plantear su renuncia, argumentando que la jubilación «es norma establecida para los obispos al doblar la curva de los setenta y cinco» ${ }^{48}$. De hecho, conforme pasan los años, la publicación va aumentando su tono crítico, llegando no solo a considerar que Pablo VI debería haberse orientado más hacia la renovación eclesial, sino también a diagnosticar su pontificado en pleno «declive» ${ }^{49}$.

Los obispos $(50,6 \%)$ representan el tema más presente en los editoriales. Vida Nueva entiende como enriquecedor el pluralismo y la comunión existente en el Colegio de los obispos ${ }^{50}$, y muestra su inclinación hacia un perfil episcopal más proclive a la renovación ${ }^{51}$. La línea editorial de Vida Nueva se muestra a favor de la jurisdicción del episcopado temporal, comparando esta forma de gobierno con el servicio que desempeñan los superiores de las órdenes religiosas: "se trata —es claro- no de un episcopado 'ad tempus', sino de una jurisdicción 'ad tempus', que no vemos cómo puede objetarse teológicamente ${ }^{52}$. En cuanto a la reforma del cónclave que se estaba planteando en aquellos momentos, el semanario propone «hacer miembros únicos del Cónclave a los presidentes de las conferencias episcopales o [...] encargar al Sínodo la elección del Romano Pontífice» ${ }^{53}$. El semanario no oculta sus referentes episcopales: Vicente

${ }^{46}$ Editorial. "Pablo VI, un difícil y exaltante destino". Vida Nueva 731 (23 de mayo de 1970): 5.

47 Editorial. "Con cariño y sin idolatría”. Vida Nueva 889 (30 de junio de 1973): 5.

48 Editorial. "Setenta y cinco años". Vida Nueva 849 (23 de septiembre de 1972): 5.

49 Editorial. "Con cariño y sin idolatría", 5.

50 Cf. LG 18-29.

51 Cf. Editorial. “134 maneras de ser católico”. Vida Nueva 675/676 (26 de abril/3 mayo de 1969): 3.

52 Editorial. “Diócesis conflictivas”. Vida Nueva 904 (27 de octubre de 1973): 45.

53 Editorial. "La reforma del Cónclave. Más difícil de lo que parece”. Vida Nueva 873 (10 de marzo de 1973): 5. 
Enrique y Tarancón y Marcelo González Martín, que para la revista son prelados que representan la comunión eclesial y que «no quieren ser encasillados, que no quieren ser obispos de los de derechas o de los de izquierdas, de los progresistas o de los integristas, sino de todos» ${ }^{54}$. De la misma forma, la revista tampoco esconde sus discrepancias con episcopados más resistentes a la renovación como Casimiro Morcillo González, arzobispo de Madrid y presidente de la $\mathrm{CEE}^{55}$.

\section{EL PAPEL DE LOS PRESBÍTEROS, RELIGIOSOS Y LAICOS}

Vida Nueva no solo cubre las noticias relacionadas con la jerarquía de la Iglesia. También muestra interés por el camino de la renovación posconciliar emprendido por el resto de los ministerios eclesiales: el orden sacerdotal $^{56}$, la vida religiosa ${ }^{57}$ y los laicos ${ }^{58}$. La tabla 2 expone la presencia de estos servicios eclesiales, y otros temas relacionados, en los editoriales de la revista:

TABLA 2

\begin{tabular}{|l|r|c|}
\hline \multicolumn{1}{|c|}{ Categorías } & $\mathbf{N}^{\mathbf{o}}$ & Porcentaje \\
\hline Clero & 107 & 29,7 \\
\hline Laicos & 59 & 16,4 \\
\hline Vida religiosa & 24 & 6,7 \\
\hline Seminarios & 18 & 5 \\
\hline Celibato sacerdotal & 10 & 2,8 \\
\hline Ministerios femeninos & 4 & 1,1 \\
\hline
\end{tabular}

${ }^{54}$ Editorial. "Hora de trabajar unidos". Vida Nueva 817 (29 de enero de 1972): 5.

55 Tras el fallecimiento de Casimiro Morcillo González, el 30 de mayo de 1971, el editorial le rinde homenaje. Como signo de respeto, la revista manifiesta la decisión de no hacer valoraciones de su episcopado. Sin embargo, anota la siguiente consideración: «No creemos descubrir ningún mediterráneo si señalamos la distancia que había entre los modos de enfocar los problemas de Vida Nueva y algunas de las posiciones adoptadas en los penúltimos años por Don Casimiro». Editorial. "A la dulce piedad de Dios". Vida Nueva 785 (5 de junio de 1971): 5.

56 Cf. LG 28; PO 1-22.

57 Cf. LG 43-47; PC 1-25.

58 Cf. LG 30-38; AA 1-33. 
Vida Nueva califica como profunda la crisis sacerdotal existente y aboga por la renovación del ministerio. El Clero es una realidad significativamente presente en los editoriales $(29,7 \%)$, sobre todo durante los años previos a la Asamblea Conjunta de obispos y sacerdotes en España y al Sínodo de los obispos sobre El sacerdocio ministerial y la justicia en el mundo, acontecimientos celebrados en 1971. La revista analiza un estudio sobre la realidad sacerdotal en España, impulsado por la Comisión Episcopal del Clero y encargado a un grupo de jesuitas del Departamento de Investigaciones Sociológicas. Vida Nueva observa «buena salud, problemática creciente; y [un] cambio ideológico» en los clérigos ${ }^{59}$, considera necesaria una reforma sin radicalismos y propone a los presbíteros que no vivan aislados del mundo e iluminen con el Evangelio el orden temporal $^{60}$. Igualmente, la revista se muestra crítica con el anticlericalismo proveniente de católicos integristas ${ }^{61}$.

Relacionados con el clero, hay tres temas cruciales en la reflexión posconciliar: la renovación de los Seminarios (5\%), el Celibato sacerdotal (2,8 $\%)$ y la reflexión sobre los Ministerios femeninos (1,1\%). Vida Nueva apuesta por la renovación de la formación de los presbíteros en el seminario a la luz del Decreto Optatam totius, que llama a la renovación de la dimensión espiritual, intelectual y pastoral de los futuros presbíteros ${ }^{62}$. Igualmente, critica a algunos formadores preocupados en exceso por el aumento del número de candidatos y les recomienda un acompañamiento que tenga

59 «Buena salud», al identificar un buen «nivel de cultura y entusiasmo», «espíritu crítico, pero no rebelde» y sinceridad al confesar los «fallos»; «problemas crecientes», en cuestiones teológicas y en la «división» sobre el celibato sacerdotal; y «cambio ideológico», en relación con la teología, autoridad, visión del mundo, vocación sacerdotal, problemas políticos y sociales, y tendencias filosóficas. Editorial. "Toda da la verdad sobre los sacerdotes". Vida Nueva 722 (21 de marzo de 1970): 3.

${ }^{60}$ Cf. Editorial. "El cura incómodo". Vida Nueva 973, (15 de marzo de 1975): 5.

${ }^{61}$ Sirva de ejemplo la crítica de Vida Nueva a la consigna "prefiero una religión sin sacerdotes», una frase citada por Blas Piñar López, procurador en las Cortes Españolas: «el señor Piñar sabe que preferir a este mal una religión sin sacerdotes será lo que sea, pero en todo caso, no es el catolicismo que tanto proclama como suyo. Los extremos se tocan, y el más alto dogmatismo termina por olvidarse de sus dogmas y el más total integrismo acaba por demostrar que no lo es, ya que prefiere el error dogmático a la claudicación de las personas y —al mismo tiempo—-plantea una opción que ni cabría caber en una cabeza ortodoxa». Editorial. "Prefiero una religión sin sacerdotes...". Vida Nueva 936 (8 de junio de 1974): 5.

62 Cf. OT 1-22. 
como objetivo el descubrimiento de «las hondas raíces» vocacionales ${ }^{63}$. En el contexto del tercer Sínodo de los obispos, la revista pone de relieve las causas de una crisis vocacional que apunta hacia una formación teológica preconciliar, a las características del ámbito educativo y familiar, y al desplazamiento de la población rural a las áreas urbanas ${ }^{64}$.

La línea editorial de Vida Nueva evoluciona hacia la opcionalidad del Celibato sacerdotal (2,8\%). A priori, la revista expresa su comunión con la Encíclica Sacerdotalis caelibatus de 1967, en la que Pablo VI ratificaba la validez de esta norma eclesial ${ }^{65}$ : «El punto de vista de Vida Nueva - que vamos a anticiparlo sin el menor rodeo- coincide plenamente con el de Pablo VI y el de la práctica totalidad del episcopado mundial» ${ }^{66}$. Sin embargo, a raíz del Concilio Pastoral de Holanda, el semanario adopta una actitud más comprensiva con la opcionalidad del celibato, medida propuesta por el episcopado holandés: «Lo que piden simplemente es la posibilidad de ordenar hombres casados - algo perfectamente tradicional en buena parte de la Iglesia- y la de permitir ministerios sagrados a algunos sacerdotes casados, con muy precisas condiciones y en muy contadas circunstancias ${ }^{67}$. Asimismo, ante la petición de la reanudación del ministerio de los presbíteros secularizados, la revista se interroga por la dispensa y una «seria reinstalación» de dichos sacerdotes en la sociedad ${ }^{68}$.

En relación con los Ministerios femeninos $(1,1 \%)$, tras el Congreso Mundial de Teología en Bruselas en 1970, Vida Nueva sugiere que el papel de la mujer en la Iglesia y su admisión a los ministerios sean examinados sin miedo, con espíritu teológico y sin integrismos que propugnen el

${ }_{63}$ Editorial. “No siempre 'entusiasmo' es 'vocación'”. Vida Nueva 665 (15 de febrero de 1969): 5 .

${ }^{64}$ Cf. Editorial. "Una moral sin raíces”. Vida Nueva 768 (30 de enero de 1971): 5; Editorial. “Seminarios, ¿vacíos?”. Vida Nueva 774 (20 de marzo de 1971): 5.

${ }^{65}$ El Concilio Vaticano II apenas menciona el celibato sacerdotal (PO 16). Sin embargo, posteriormente, Pablo VI afronta este tema exponiendo la importancia, los fundamentos y las razones cristológicas, eclesiológicas y escatológicas del celibato de los presbíteros. Cf. Pablo VI. "Encíclica Sacerdotalis Caelibatus". La Santa Sede. 24 de junio de 1967. Consultado el 23 de diciembre de 2019, 19-34. http://www.vatican. va/content/paul-vi/es/encyclicals/documents/hf_p-vi_enc_24061967_sacerdotalis.html

${ }^{66}$ Editorial. "Sacerdotes secularizados". Vida Nueva 712 (10 de enero de 1970): 20.

67 Editorial. "Holanda: no un cisma, pero sí un conflicto". Vida Nueva 715 (31 de enero de 1970): 5.

${ }^{68}$ Editorial. "Un orden de factores que sí altera el producto". Vida Nueva 717 (14 de febrero de 1970): 5. 
obstat sexus ${ }^{69}$. No obstante, ante la propuesta de George Bernard Flahiff, cardenal de Winnipeg (Canadá), en el tercer Sínodo de los obispos sobre el estudio del sacerdocio femenino ${ }^{70}$, el semanario considera que el debate sobre el papel de la mujer en la Iglesia es un tema más apremiante. Porque, para la revista, por encima del planteamiento de los ministerios femeninos, hay un asunto todavía más urgente: el reconocimiento de la concepción del ser humano basado en «la igualdad fundamental de los dos sexos $)^{71}$.

Vida Nueva también pone de relieve la crisis y transformación que estaba atravesando la Vida religiosa $(6,7 \%)$ en el posconcilio, una cuestión abordada por el Decreto Perfectae Caritatis ${ }^{72}$. En esa línea, el semanario plantea el cultivo del espíritu evangélico y la formación, e insiste en la idea de que el proceso de reforma sea realizado «sin nervios, sin snobismos, con inteligencia ${ }^{73}$. La revista también advierte el profundo cambio que estaba experimentando la vocación femenina: «las monjas jóvenes invaden las universidades, entran en los conventos la televisión y la prensa, los cursillos de navidad o verano se multiplican por todas partes ${ }^{74}$. Y, en relación con la tensión surgida entre Pablo VI y la Compañía de Jesús relativa a la desaparición de los grados en la XXXII Congregación General en 1975, Vida Nueva mantiene una actitud mediadora y equilibrada:

«Es evidente que los jesuitas han tenido serias razones para plantear el problema de la desaparición de los grados en la Compañía. Bastaría pensar en los dolores de aquellos a quienes esa diferencia humilla; en la resistencia que el hombre de hoy siente ante la forma de discriminación; en la necesidad de valorar apostólicamente el trabajo de los hermanos seglares; en el expreso mandato conciliar de que todos, en el interior de las órdenes, vivan 'en igualdad de condiciones, derechos y deberes, excepto los que provienen del orden sagrado'.

Pero también es evidente que Pablo VI no se ha opuesto a ese cambio por una atadura intolerante al pasado y que ha contado, en cambio,

${ }^{69}$ Cf. Editorial. “Obstat sexus”. Vida Nueva 750 (3 de octubre de 1970): 3.

${ }^{70}$ Cf. Philip Wallace Platt. Gentle Eminence. A life of Cardinal Flahiff. Québec: McGill-Queen's University Press, 1999, 3-4.

${ }^{71}$ Editorial. “La mujer ¿tema candente?”. Vida Nueva 803 (23 de octubre de 1971): 5 .

72 Cf. PC 2-5.

73 Editorial. "Las monjas: 'del cero al infinito”'. Vida Nueva 772 (6 de marzo de 1971): 5 .

${ }^{74}$ Íd. 
con serias razones para mantener, al menos hoy por hoy, intocada la fórmula ignaciana. Vivimos momentos de una seria devaluación del sacerdocio ministerial de la Compañía ¿no podría ayudar a un acentuarse de esa devaluación, dado el peso ejemplar que los jesuitas tienen hoy en todo el resto de la Iglesia? La tendencia realmente existente hoy y en la que algunos jesuitas a la hora de la ordenación desean permanecer jesuitas pero sin recibir las órdenes sacerdotales, ¿no nos conducirá en el año 2.000 a una compañía convertida mayoritariamente en un instituto secular? ${ }^{75}$.

Asimismo, Vida Nueva apuesta por la implicación de los Laicos (16,4\%) en la vida de la Iglesia ${ }^{76}$. Su línea editorial permanece en desacuerdo con un enfoque eclesial que reduce la Iglesia a jerarquía ${ }^{77}$. Por ello, el semanario fomenta la participación de toda la comunidad eclesial y se muestra crítico con la escasa responsabilidad de los laicos. Sirva como ejemplo los argumentos pronunciados por Antonio Montero, obispo auxiliar de Sevilla y cofundador de Vida Nueva, en una conferencia. La revista hace suyas las palabras del prelado para ahondar en la reflexión sobre el modesto papel que seguían adoptando los laicos en la Iglesia española: «En un diagnóstico intuitivo puedo dejar constancia de que el 30 por ciento de nuestra diócesis tiene un contacto habitual con la Iglesia y el 70 por ciento no son cristianos actores, sino espectadores ${ }^{78}$. Otro editorial hace un llamamiento a una participación decisiva de los laicos en el organigrama de la Iglesia:

«No creemos descubrir ningún mediterráneo si aseguramos que uno de los aspectos de ese posible dique-anti es la excesiva clericalización de las diócesis en las que únicamente el obispo, su curia y el clero - y no todo ni en la misma medida- tienen voz y voto en la marcha de la Iglesia local. Una inmensa mayoría de la Iglesia, los seglares, siguen de espaldas, forzadamente de espaldas, al gobierno de la diócesis» ${ }^{79}$.

75 Editorial. "Pablo VI y los jesuitas". Vida Nueva 974 (22 de marzo de 1975): 5.

76 Cf. AA 2.

77 Cf. Editorial. “Década del 70: ¿Qué esperan los seglares?”. Vida Nueva 729 (9 de mayo de 1970): 5.

78 Editorial. “Actores y espectadores". Vida Nueva 902 (13 de octubre de 1973): 5.

79 Editorial. "Los seglares también son diócesis". Vida Nueva 736 (27 de junio de 1970): 5. 


\section{EL CAMINO DE LA RENOVACIÓN POSCONCILIAR}

La línea editorial de la revista revela de manera explícita la creencia del equipo de Vida Nueva en el Concilio Vaticano II, «en su espíritu y en su letra ${ }^{80}$. La tabla 3 muestra categorías analizadas relativas a la renovación de la Iglesia en el periodo posconciliar:

TABLA 3

\begin{tabular}{|l|r|c|}
\hline \multicolumn{1}{|c|}{ Categorías } & $\mathbf{N}^{\mathbf{0}}$ & Porcentaje \\
\hline Concilio Vaticano II & 121 & 33,6 \\
\hline Renovación & 100 & 27,8 \\
\hline Corrientes eclesiales & 60 & 16,7 \\
\hline Teología & 59 & 16,4 \\
\hline Magisterio & 56 & 15,6 \\
\hline Renovación: liturgia/sacramentos & 34 & 9,4 \\
\hline Preconcilio & 23 & 6,4 \\
\hline Signos de los tiempos & 23 & 6,4 \\
\hline Organización & 14 & 3,9 \\
\hline Formación & 13 & 3,6 \\
\hline Renovación: métodos & 12 & 3,3 \\
\hline Renovación: lenguajes & 7 & 1,9 \\
\hline Renovación: catequesis & 7 & 1,9 \\
\hline Sentido de pertenencia & 7 & 1,9 \\
\hline Devoción mariana & 6 & 1,7 \\
\hline
\end{tabular}

Vida Nueva aboga por llevar a cabo sin prisas la Renovación, tema presente en un 27,8\% de los editoriales. Los documentos del Concilio Vaticano II $(33,6 \%)$ representan para la revista un valor intrínseco al proyecto de renovación, que tiene un punto de referencia fundamental: la vuelta al origen, es decir, al Evangelio. De ahí que la revista se considere

\footnotetext{
${ }^{80}$ Editorial. "Creemos en el Vaticano II". Vida Nueva 655 (7 de diciembre de 1968): 5 .
} 
al mismo tiempo "conciliar y tradicional antes del Concilio»; conciliar, porque «cree en la necesidad de renovar la Iglesia»; tradicional, porque fragua una renovación que «solo puede venir por un verdadero regreso a las raíces evangélicas» ${ }^{81}$. El semanario considera que la Iglesia ha de estar atenta a los Signos de los tiempos $(6,4 \%)$. Y, apostando por el pluralismo y la apertura a las diferentes Corrientes eclesiales (16,7\%), estima que un signo de los tiempos del momento corresponde a «la amplísima gama de colores y matices que hay en las comunidades» ${ }^{82}$.

La revista promete "clamar y clamar" la fe en el Concilio Vaticano II $(33,6 \%)$ que significa «la forma viva del paso de Cristo por nuestro siglo $[\mathrm{XX}]^{83}$. En este sentido, el semanario sostiene que el Concilio es la «herencia sagrada» de Juan XXIII, y niega que «el Papa Montini hubiera echado agua al vino del Papa Roncalli» ${ }^{84}$. Ante las polémicas surgidas en referencia a la aplicación del Concilio, el semanario muestra su Sentido de pertenencia eclesial $(1,9 \%)$ y, preocupándose por la defensa del Magisterio $(15,6 \%)$, critica a aquellos que mantienen ideas y actitudes preconciliares (Preconcilio, 6,4\%). En esta línea, la revista subraya que la verdadera herejía posconciliar es «la falta de fe» y considera que aún queda un largo camino por recorrer para la aplicación del Concilio Vaticano II:

«Nosotros que, con todos los perdones, seguimos creyendo en el Vaticano II, antes del parto, en el parto y después del parto, nos sentimos hoy orgullosos de aquella gran aventura de los espíritus y no estamos decepcionados de su aplicación, aun cuando creemos que aún falta mucho camino - la mayoría- por recorrer» ${ }^{85}$.

Para conmemorar los diez años del Concilio, la revista subraya sus valores y muestra su confianza en la llegada del Concilio Vaticano III cuando definitivamente se llevase a cabo el Vaticano II:

«La mediocridad del fruto de estos diez años en nada debe ni puede ensuciar la calidad de aquella semilla. Nosotros seguimos teniendo una

\footnotetext{
${ }^{81}$ Martín Descalzo. "Qué ha sido", 7.

82 Editorial. "Breves notas para una conclusión”. Vida Nueva 730 (17 de mayo de 1970): 31.

83 Íd.

84 Editorial. "La herencia de Juan XXIII". Vida Nueva 852 (14 de octubre de 1972): 5.

85 Íd.
} 
total y absoluta fe en ella. Sabemos que, si en el campo hay cizaña, no es porque el sembrador esparciera semillas de segunda calidad, sino porque el enemigo malo sembró cizaña en la noche y porque nosotros alimentamos con tanto amor esa cizaña como el trigo bueno. Seguimos por tanto creyendo en la teología del Pueblo de Dios; seguimos teniendo fe en esa colegialidad nunca realizada; seguimos confiando en la apertura de la Iglesia a las realidades terrenas sin renunciar, por ello, al Evangelio; seguimos defendiendo la libertad religiosa y la obligada defensa de los derechos del hombre; seguimos esperando una liturgia más auténtica; seguimos necesitando el regreso a la viva Palabra de Dios.

Tal vez una década es sólo una década. Un día habrá un Vaticano III. Nos gustaría conocerlo, pero no tenemos demasiada prisa en su llegada. Aún no hemos hecho fructificar ni la décima parte del II. La tarea sigue. Y nosotros creemos radicalmente en ella» ${ }^{86}$.

La renovación se proyecta transversalmente en los editoriales, cuyos contenidos reflejan el espíritu de los decretos, declaraciones y constituciones del Concilio Vaticano II. Igualmente, otros textos aluden de manera directa al camino de la reforma eclesial, que no consiste meramente en la transformación de la Organización y forma de gobierno de la Iglesia $(3,9 \%)$, sino también en la renovación de la Teología $(16,4 \%)$, la liturgia (Renovación: liturgia/sacramentos 9,4\%), los métodos pastorales (Renovación: métodos, 3,3\%), el ámbito catequético (Renovación: catequesis, 1,9\%) y el uso del lenguaje (Renovación: lenguajes, 1,9\%). El semanario considera que «el futuro de la renovación espiritual de un país lo señala - como un termómetro de anticipación- el presente de su teología» ${ }^{87}$. Sin embargo, la revista estima que el desarrollo de la teología en España es insuficiente, en contraste con otros países como Francia o Alemania. Y muestra interés por los teólogos próximos a la renovación, especialmente por los más jóvenes que apuestan por la aplicación y divulgación del Concilio Vaticano II. Catalogándolos como «alféreces provisionales de la teología»:

«Alféreces por su audacia, provisionales por su juventud. Hijos también ellos de un país teológicamente venido a menos, obligados a

${ }^{86}$ Editorial. “iDiez años ya, Dios Santo!”. Vida Nueva 1008 (13 de diciembre de 1975): 5 .

${ }^{87}$ Editorial. "Nuestros alféreces provisionales de la teología". Vida Nueva 662 (25 de enero de 1969): 5. 
enfrentarse al mismo tiempo con docenas de problemas que en otros países se fueron presentando gradualmente a lo largo de los siglos: el cambio de métodos aportado por las ciencias modernas, la formación de un nuevo lenguaje en todos los ámbitos intelectuales (tanto más grave en un país donde existe una tal desconexión entre universidades religiosas y civiles), el enfoque pastoral y concreto exigido a la teología después del Vaticano II ${ }^{88}$.

La labor de los teólogos es trascendental para una revista que, a la luz del Decreto Apostolicam Actuositatem ${ }^{89}$, piensa que «la primera renovación que la Iglesia necesita es — antes incluso que la de los corazonesla renovación de las cabezas ${ }^{90}$. Porque para la publicación, muchas de las polémicas y divisiones eclesiales del posconcilio obedecen a la falta de reflexión ${ }^{91}$. De ahí que el semanario, abogue en sus editoriales por la Formación $(3,6 \%)$ de los miembros de la comunidad eclesial.

La revista subraya algunos discursos de Pablo VI que, en clave de renovación conciliar, fueron dirigidos hacia la Iglesia española. Uno de ellos, evaluado por el semanario, es pronunciado con ocasión de la Fiesta de Santiago Apóstol en 1971: «En él hay —nos parece-dos afirmaciones fundamentales: un acto de fe en la religiosidad tradicional española; y una no menos clara exhortación hacia una renovación en profundidad ${ }^{92}$. No obstante, como hemos señalado anteriormente, la jerarquía de la Iglesia española ya había ido recibiendo el Concilio e intentándolo adaptar a su realidad eclesial y social. De ahí que Vida Nueva valore ese impulso: "Que nuestra jerarquía ha tomado, ya del Concilio para acá — pero acentuándolo especialmente en los dos últimos años-una línea de compromiso, renovación, de puesta al día, es algo que sólo un insensato puede desconocer» ${ }^{93}$.

Más allá de caer en estereotipos en el uso del lenguaje (Renovación: lenguajes, 1,9\%), como el de "progresistas e integristas», y criticando

88 Íd.

89 Cf. AA 32.

90 Editorial. "Verano caliente". Vida Nueva 838 (24 de junio de 1972): 5.

91 Cf. Íd.

92 Editorial. "Un nuevo mensaje de Pablo VI a España". Vida Nueva 793 (31 de julio de 1971): 5.

93 Editorial. "Cuatro palabras del Papa". Vida Nueva 836 (10 de junio de 1972): 5. 
los «excesos de un lado y otro» de las corrientes eclesiales, la línea editorial de Vida Nueva desea "tener una postura incuestionablemente renovadora ${ }^{94}$. En este sentido, para Vida Nueva, Pablo VI es un referente al presentar un estilo "humilde, dialogal, inteligente y reflexivo» ${ }^{95}$. Asimismo, el semanario estima que el lenguaje utilizado por presbíteros y obispos en las predicaciones y cartas pastorales ha de evolucionar: "¡Cuántos sermones sin preparar, cuántas pastorales escritas de oficio y sin nada que decir, qué inflación de documentos escritos muchas veces por pura rutina!» ${ }^{96}$.

Igualmente, según Vida Nueva, los nuevos métodos (Renovación: métodos, 3,3\%) en el campo de la teología pastoral también suponen un reto para la Iglesia. Sirva de ejemplo un editorial donde la revista analiza las consecuencias, los riesgos y los métodos de evangelización a partir de cuatro principios enunciados por Pablo VI: «no servirse de la preponderancia de los demás, bien sea pública o privada, para defender las propias posiciones religiosas»; «no favorecer la opresión de la gente a la que llevan el mensaje evangélico»; «no dejar sin deploración las malas acciones perpetradas contra poblaciones indefensas», y "compartir incluso las pruebas y sufrimientos de esas mismas poblaciones injustamente tratadas ${ }^{97}$.

Para Vida Nueva, en la línea de la Constitución Sacrosanctum Concilium, la reforma de la liturgia (Renovación: liturgia/sacramentos, 9,4\%) es una cuestión fundamental ${ }^{98}$. La revista desea que las celebraciones tengan menos carga ritual, de tal manera que los sacramentos se vivan con mayor hondura. Particularmente, el semanario presta atención a las reformas de los rituales y celebraciones del Bautismo, Penitencia y Eucaristía, estimulando en este último sacramento una actitud más celebrativa y participativa de la asamblea: "Y hemos conseguido algo, hemos logrado incluso mucho; los fieles han pasado de asistir a entender; pero ¿a cuántos cientos de kilómetros estamos aún de una verdadera

94 Editorial. "La idolatría de los medios". Vida Nueva 713 (17 de enero de 1970): 5.

95 Editorial. "La carta de Pablo VI... El cristal con que se mira”. Vida Nueva 783 (22 de mayo de 1971): 5.

96 Íd.

97 Editorial. "El riesgo de evangelizar". Vida Nueva 893 (28 de julio de 1973): 5.

98 SC 1. 
participación?»99. La revista, deseando que se rompa ese «muro de Berlín que separaba al sacerdote del pueblo, reduciéndolos a celebrante y oyentes», aboga por una aproximación a las celebraciones de los primeros cristianos: «¿Quién se atrevería a comparar, aún de lejos, la atmósfera de nuestras misas con la que el Evangelio de Juan nos transmite de la cena del Señor? ${ }^{100}$.

El semanario también trata la Devoción mariana $(1,7 \%)$ en sus editoriales, posicionándose a favor del modo en el que abordó la figura de María el Concilio Vaticano II $^{101}$. La revista aboga por una revisión de algunas prácticas de devoción mariana y, a la luz de la Exhortación Apostólica Marialis cultus ${ }^{102}$, destaca tres ideas fundamentales: la evolución de la renovación litúrgica que, según Vida Nueva, «no ha disminuido sino centrado la devoción mariana»; «las desviaciones de piedad marianas», debido a las ocasiones en las que se había separado "el culto de la Virgen de su necesario punto de referencia: Cristo»; y «la presentación de María como una mujer de nuestro siglo $[\mathrm{XX}]{ }^{103}$.

\section{LA EVANGELIZACIÓN EN UN MUNDO SECULARIZADO}

Para Vida Nueva, la transmisión del Evangelio es un tema capital en un nuevo periodo donde la secularización es uno de los problemas más prioritarios en el ámbito pastoral. La tabla 4 indica la presencia de algunos temas relacionados con la tarea evangelizadora de la Iglesia en los editoriales de Vida Nueva:

99 Editorial. "Encaje de bolillos". Vida Nueva 708 (13 de diciembre de 1969): 5.

100 Íd.

101 En el Concilio, se debatió entre reservar el tema mariano para un documento específico o incluirlo en el esquema De Ecclesia - la Constitución Dogmática Lumen Gentium sobre la Iglesia-. Finalmente, el Concilio incluyó a María en el capítulo octavo de la Constitución sobre la Iglesia (LG 52-69; Giuseppe Alberigo. Historia del Concilio Vaticano II. Vol. III. Salamanca: Sígueme/Peeters, 2006, 97-100).

102 Cf. Pablo VI. "Exhortación Apostólica Marialis Cultus". La Santa Sede. 2 de febrero de 1974. Consultado el 23 de diciembre de 2019. http://www.vatican.va/content/paul-vi/es/apost_exhortations/documents/hf_p-vi_exh_19740202_marialis-cultus.html

103 Editorial. "María del siglo XX". Vida Nueva 926 (30 de marzo de 1974): 5. 
TABLA 4

\begin{tabular}{|l|r|c|}
\hline \multicolumn{1}{|c|}{ Categorías } & $\mathbf{N}^{\mathbf{o}}$ & Porcentaje \\
\hline Evangelización & 114 & 31,7 \\
\hline Fe y espiritualidad & 100 & 27,8 \\
\hline Ateísmo y secularización & 25 & 6,9 \\
\hline Tiempos litúrgicos & 23 & 6,4 \\
\hline
\end{tabular}

En los editoriales de la revista subyace la Constitución Gaudium et spes, sobre todo al presentar la experiencia religiosa (Fe y espiritualidad, $27,8 \%$ ) y el anuncio del Evangelio (Evangelización, 31,7\%) como realidades complementarias con los derechos humanos, la justicia y la doctrina social de la Iglesia. En este sentido, insistiendo en la importancia de la praxis cristiana, el semanario presta especial atención a los enfoques temáticos del Sínodo de los obispos sobre El sacerdocio ministerial y la justicia en el mundo en 1971, a la dirección del Sínodo sobre La evangelización en el mundo moderno en 1974 y a los contenidos del documento de la CEE sobre La Iglesia y la comunidad política ${ }^{104}$. Sirva de ejemplo un editorial en el que la acción social es entendida como parte intrínseca de la evangelización:

«La actividad misionera debe ser concebida con perspectivas amplias y modernas [...]. La respuesta no puede ser unívoca, sino dictada por la experiencia, la posibilidad y el modo de actuar vigilante y paciente. En la práctica, el empleo de los medios de orden temporal, puede tener una prioridad pastoral, aun cuando la evangelización conserve su prioridad esencial e intencional.

Esas actividades elevadas al nivel de la caridad, son también ellas evangelización. Trabajar cristianamente, es ya orar. Amar cristianamente es ya evangelizar» ${ }^{105}$.

Además, Vida Nueva no solo desea eliminar la dicotomía entre «espiritualismo" y «temporalismo» en la evangelización, sino que también asume la opción preferencial por los pobres como tarea de la Iglesia en su acción pastoral, ya que «la salvación, tal como se revela en la Sagrada

${ }^{104}$ Cf. Conferencia Episcopal Española. La Iglesia y la comunidad política: documentos de la XVII Asamblea Plenaria del Episcopado Español. Madrid: PPC, 1973.

105 Editorial. "No son un dilema". Vida Nueva 751 (10 de octubre de 1970): 3. 
Escritura, no es una salvación ahistórica a la que se le añade justicia como algo previo o posterior; se trata, por el contrario, de una acción de justicia en favor de los débiles y oprimidos del mundo» ${ }^{106}$. Asimismo, la revista depara en las dificultades que encuentra la Iglesia misionera por la falta de recursos humanos y económicos. El semanario considera que «las misiones son parte - y muy sustancial — de un verdadero compromiso cristiano». De ahí que señale que la raíz del problema esté en el debilitamiento «de la conciencia misionera en los pueblos de vieja tradición cristiana. Es ahí donde está la crisis, es ahí donde está el problema» ${ }^{107}$.

Vida Nueva se preocupa por una sociedad cada vez menos creyente (Ateísmo y secularización, 6,9\%). Al igual que la Constitución Gaudium et spes, la revista ahonda en las raíces del ateísmo ${ }^{108}$ y pone de relieve el «aumento de la duda y del mismo ateísmo confesado en Europa». El semanario alude al "proceso de la secularización de la Navidad», que en los últimos tiempos «se ha acelerado». Y narra una anécdota que relata cómo en la fachada principal de una Iglesia apareció «un enorme cartel que, con letras de a metro, gritaba: por favor, no eche a Cristo de sus Navidades ${ }^{109}$.

Por consiguiente, Vida Nueva presta una notable importancia al modo cristiano de vivir la fe, y considera que el Jubileo proclamado por Pablo VI en 1975 como Año Santo de Renovación y Reconciliación representa una oportunidad para la fe y el compromiso de los cristianos: "Cuando Pablo VI entiende el Año Santo como un movimiento profético no se equivoca» ${ }^{110}$. El semanario considera que parte de la culpa de la crisis de fe recae sobre la labor pastoral de la Iglesia, advirtiendo: «No hemos sabido convertir nuestras Iglesias en casas de esperanza, más atractivas que el sol» ${ }^{111}$. Por ello, propone la vivencia de los Tiempos litúrgicos $(6,4 \%)$ como camino para crecer en la fe y en «un cristianismo más auténtico, más fiel a su testimonio de Cristo en el mundo» ${ }^{112}$.

${ }^{106}$ Cita del cardenal Tarancón en el Sínodo de los obispos, II Asamblea General Ordinaria, El sacerdocio ministerial y la justicia en el mundo. Editorial. "Frente a toda esclavitud". Vida Nueva 820 (19 de febrero de 1972): 5.

107 Editorial. "No es un asunto de chinitos". Vida Nueva 903 (20 de octubre de 1973): 5.

108 Cf. GS 19, 20, 21.

109 Editorial. "Navidades sin Cristo”. Vida Nueva 961 (21 de diciembre de 1974): 5.

110 Editorial. “¿Diez años ya!”, 5.

111 Editorial. "La Pascua, otra vez”. Vida Nueva 778 (17 de abril de 1971): 5.

112 Editorial. "Un tiempo apasionante". Vida Nueva 697 (27 de septiembre de 1969): 5. 


\section{LOS PLANTEAMIENTOS DE LA DOCTRINA SOCIAL DE LA IGLESIA}

Vida Nueva tiene presente la dimensión social de la fe en numerosos editoriales, sobre todo al intentar aplicar los principios magisteriales al ámbito social, político, económico y cultural. La tabla 5 muestra las frecuencias relacionadas con esta realidad:

TABLA 5

\begin{tabular}{|l|r|c|}
\hline \multicolumn{1}{|c|}{ Categorías } & $\mathbf{N}^{\mathbf{o}}$ & Porcentaje \\
\hline Doctrina social & 59 & 16,4 \\
\hline Movilización & 8 & 2,2 \\
\hline Riquezas/patrimonio & 6 & 1,7 \\
\hline
\end{tabular}

El compromiso de la revista con los problemas sociales ocasiona al equipo de Vida Nueva dificultades con el Régimen. El semanario es objeto de un secuestro y tres sanciones, una de ellas contra un editorial que alienta a los ciudadanos a celebrar el Día Internacional de los Trabajadores $^{113}$. A ello hay que sumar que Vida Nueva no tiene como fin ser exclusivamente una publicación de contenidos eclesiales. En este sentido, su director argumenta que la revista es de información general y religiosa por una razón burocrática. Sin embargo, aquella razón traspasó las fronteras de la burocracia, ya que la revista había optado por atenerse a la legislación común para poder hacerse eco de contenidos relativos al orden temporal ${ }^{114}$.

Aunque el tema de la participación de la Iglesia en las manifestaciones donde se implica la comunidad de creyentes no es muy frecuente (Movilización, 2,2\%), los editoriales apelan a la movilización de los cristianos en relación con la defensa de los derechos de los obreros ante las precarias situaciones laborales ${ }^{115}$. Otro tema poco presente es el de la gestión de las Riquezas/patrimonio $(1,7 \%)$, donde la revista expresa

113 Cf. Editorial. "Las cuatro caras de una fecha". Vida Nueva 727 (26 de abril de 1970): 5 .

114 Cf. Martín Descalzo. "Qué ha sido", 5.

115 Cf. Editorial. "Las cuatro caras de una fecha". Vida Nueva 727 (26 de abril de 1970): 5 . 
su visión crítica sobre la financiación de la Iglesia, poniendo de relieve la opción preferencial por los pobres ${ }^{116}$.

Además de tener una mirada social sobre los problemas de España y del mundo en sus páginas ${ }^{117}$, Vida Nueva cita documentos de la doctrina social (59\%). En sus editoriales, trata el 80 aniversario de la publicación de la Carta Encíclica Rerum novarum ${ }^{118}$, la Carta Apostólica Octogesima adveniens ${ }^{119}$, los 10 años de la Carta Encíclica Pacem in terris ${ }^{120}$ y la Carta Encíclica Populorum Progressio ${ }^{121}$, vinculando este último documento a la defensa de los excluidos, la promoción de los derechos humanos y la lucha por la justicia social. El semanario espera que este documento sea algo más que «una Encíclica traspapelada, útil para algunas citas, pero radicalmente inutilizada para lo que quiso ser: un instrumento" ${ }^{122}$. No obstante, el editorialista alude a iniciativas vinculadas a aquella Encíclica, como la creación de la Comisión Iustitia et Pax, la Comisión Promoción Humana o la cooperación de la Santa Sede para el desarrollo de Biafra — República del sudeste de Nigeria entre 1967 y 1970 - ${ }^{123}$.

Otro editorial introduce la Carta Apostólica Octogesima adveniens ${ }^{124}$, que conmemora el 80 aniversario de la publicación de la Carta Encíclica

116 Cf. Editorial. "Nuestra Iglesia de los pobres". Vida Nueva 734/735 (13/20 de junio de 1970): 3-4.

117 La Gaudium et spes hace un llamamiento a integrar la actividad humana en el misterio de la fe y fomentar el compromiso y misión de la Iglesia con las realidades temporales. Cf. GS 36, 38, 43, 76.

118 Cf. León XIII. "Carta Encíclica Rerum novarum”. La Santa Sede. 5 de mayo de 1891. Consultado el 23 de diciembre de 2019. http://www.vatican.va/content/leo-xiii/ es/encyclicals/documents/hf_l-xiii_enc_15051891_rerum-novarum.html

119 Cf. Pablo VI. "Carta Apostólica Octogesima adveniens". La Santa Sede. 14 de mayo de 1971. Consultado el 23 de diciembre de 2019. http://w2.vatican.va/content/ paul-vi/es/apost_letters/documents/hf_p-vi_apl_19710514_octogesima-adveniens.html

120 Cf. Juan XXIII. "Carta Encíclica Pacem in Terris". La Santa Sede. 11 de abril de 1963. Consultado el 23 de diciembre de 2019. http://www.vatican.va/content/john-xxiii/es/encyclicals/documents/hf_j-xxiii_enc_11041963_pacem.html

121 Cf. Pablo VI. "Carta Encíclica Populorum Progressio". La Santa Sede. 26 de marzo de 1967. Consultado el 23 de diciembre de 2019. http://www.vatican.va/content/paul-vi/es/encyclicals/documents/hf_p-vi_enc_26031967_populorum.html

${ }_{122}$ Editorial. "La encíclica traspapelada”. Vida Nueva 670 (22 de marzo de 1969): 5.

123 Cf. Íd.

124 Cf. Pablo VI. "Carta Apostólica Octogesima”. 
Rerum novarum ${ }^{125}$. La revista, con sentido crítico, cita al papa preguntándose por la deontología en el área de los medios de comunicación a la luz de los contenidos del documento:

«¿Cómo no se va a preguntar uno entonces sobre los detentores reales de este poder, sobre los fines que persiguen y los medios que ponen en práctica, sobre la repercusión de su acción en cuanto al ejercicio de las libertades individuales, tanto en los campos político e ideológico, como en la vida social, económica y cultural?» ${ }^{126}$.

Celebrando los 10 años de Pacem in terris ${ }^{127}$, cita el documento para poner de manifiesto la importancia de la paz y el respeto de los derechos humanos en clave nacional. Porque, para Vida Nueva, las discriminaciones y opresiones de índole política son «un delito de lesa cristiandad, más aún: de lesa humanidad» ${ }^{128}$. En esta línea, la revista se hace eco de las conclusiones aprobadas en la Asamblea Europea de sacerdotes en 1971 relativas al compromiso político de la Iglesia, del sacerdote y del cristiano. El editorial expone las conclusiones a las que allí se habían llegado: la Iglesia «no puede ni vivir ni predicar el Evangelio en su totalidad sin tomar posiciones comprometidas, como las tomaron Cristo y los profetas, ante los hechos concretos de injusticia, de opresión, de armamentismo...». De esta manera, Vida Nueva sugiere el camino que la comunidad eclesial podría emprender:

«Un cristiano que por principio nunca se mete en líos, es simplemente porque no es cristiano. El silencio es la complicidad, porque donde quiera que el cristiano viva hay injusticias que denunciar y un mundo mejor que construir. Solo en el cielo será lícito olvidarse de la misión profética y denunciadora. [...] Renunciar a esta función 'crítica de la sociedad' es, nos parece, una grave traición a su misión evangélica» ${ }^{129}$.

125 Cf. León XIII. "Carta Encíclica Rerum”.

126 Editorial. "La carta de Pablo VI", 5.

127 Cf. Juan XXIII. "Carta Encíclica Pacem”.

128 Editorial. "Diez años de la Pacem in Terris... Y la paz (la verdadera) no vino". Vida Nueva 879 (21 de abril de 1973): 5.

129 Editorial. "Una Iglesia políticamente libre". Vida Nueva 780 (1 de mayo de 1971): 5 . 


\section{LA SENSIBILIDAD ECUMÉNICA}

La revista también aborda en sus editoriales las relaciones entre creyentes de las distintas confesiones cristianas y de diferentes tradiciones religiosas. La tabla 6 indica la presencia de esta realidad en los editoriales de Vida Nueva:

TABLA 6

\begin{tabular}{|l|c|c|}
\hline \multicolumn{1}{|c|}{ Categorías } & $\mathbf{N}^{\mathbf{o}}$ & Porcentaje \\
\hline Ecumenismo & 26 & 7,2 \\
\hline Diálogo interreligioso & 4 & 1,1 \\
\hline
\end{tabular}

A la escasa cantidad de cristianos protestantes, anglicanos u ortodoxos en España, había que sumarle el obstáculo de la privación de la libertad religiosa impuesto por el Régimen, que impedía que los creyentes de confesión distinta a la católica tuvieran el derecho a estar presentes en la vida pública. No obstante, el semanario considera que dentro de la Iglesia se ha avanzado en «respeto, en comprensión, hacia los no católicos» ${ }^{130}$. Y, a la luz del Decreto Unitatis redintegratio ${ }^{131}$, aboga por la comunión y el rechazo de todo tipo de actitud integrista hacia las otras confesiones religiosas (Ecumenismo 7,2\%):

«Si buscamos la unión es "para" algo. Y ese "algo" es indiscutiblemente el mejor servicio al mundo, el más limpio testimonio de Cristo al servicio de los hombres [...]. Claro que esto supondría que quienes estamos ya sentados junto al Evangelio, en el altar o en los primeros bancos, estuviéramos en realidad "en el Evangelio" "132.

En sus editoriales, la revista valora aquellas instituciones, encuentros o jornadas que fomentan el ecumenismo. El semanario pone de relieve la Semana de la Unidad de los cristianos y su aportación a la comunión, aunque en 1971 se muestra crítico con su programa por ser una semana «más apagada que nunca»: "podría ser útil si al menos fuera la semana

${ }^{130}$ Editorial. "El escándalo de las separaciones". Vida Nueva 661 (18 de enero de 1969): 5.

131 Cf. UR 1-24.

132 Editorial. "El viaje del 'mariscal”. Vida Nueva 681 (7 de junio de 1969): 5. 
de la vergüenza. Vergüenza de no haber hecho más, de la vergüenza de seguir dormidos, de la vergüenza de seguir a gusto sabiendo que seguimos desunidos» ${ }^{133}$.

Asimismo, según Vida Nueva, la Comunidad de Taizé (Francia) representa una contribución fundamental para el ecumenismo y considera relevante que el movimiento ecuménico haya llegado a la vida de los jóvenes: «Declinaron los tiempos del ecumenismo romántico, pero son cada vez más los jóvenes que buscan un ecumenismo de profundidad ${ }^{134}$. La revista define Taizé como «un triángulo de dos rostros y un punto de apoyo»: Cristo es el punto de apoyo; y los dos rostros representan la contemplación y el compromiso. De ahí que, para el semanario, la atmósfera litúrgica de Taizé vaya más allá del «ritualismo» ${ }^{135}$. En otro editorial, la revista responde a la pregunta que en alguna ocasión se había hecho el hermano Roger, fundador de Taizé, cuestionándose por qué la juventud acudía a aquella colina para celebrar el llamado Concilio de los jóvenes: porque «el Concilio no es confesional», porque en «Taizé se escucha a los jóvenes»; por su «autenticidad»; porque «Taizé no se institucionaliza, ni se convertirá en una burocracia», y por su pobreza «no solo en medios - ya es bastante-, sino también -más importante todavía- en doctrinarismos y en recetas prefabricadas ${ }^{136}$.

La labor del Consejo Ecuménico de Iglesias también es evaluada por la revista. En ocasión del XXV aniversario de su fundación, el semanario considera que los tiempos han cambiado, ya que «aquel día [el 23 de agosto de 1948] no hubo en Ámsterdam ni siquiera observadores católicos». La revista hace un balance de la organización, celebrando que ya era "vista como positiva por los católicos sin reparo alguno». Sin embargo, el semanario destaca que años atrás solía ser catalogada "como una antiiglesia, como una encarnación de todas las herejías que se reunían para mejor combatir al catolicismo» ${ }^{137}$.

133 Editorial. "La Iglesia, que Dios ha unido... no la desunamos los cristianos". Vida Nueva 766 (23 de enero de 1971): 5.

134 Editorial. "18.000 jóvenes celebran la Pascua". Vida Nueva 880 (28 de abril de 1973): 5 .

135 Íd.

136 Editorial. "La esperanza joven de Taizé". Vida Nueva 946 (31 de agosto/8 de septiembre de 1974): 5.

137 Editorial. "Veinticinco años del Consejo Ecuménico de Iglesias". Vida Nueva 896 (1 de septiembre de 1973): 5. 
En tiempos en los que el ecumenismo era una realidad novedosa en España, Vida Nueva lo promueve. Tal es el caso de la participación de Antonio Briva Mirabent, obispo de Astorga y Presidente del Secretariado Nacional de Ecumenismo en el LII Sínodo de la Iglesia Evangélica. La revista aprovecha aquel evento para promover el encuentro entre los miembros de las distintas confesiones, ya que de ese modo «conoceremos mejor el pensamiento de los hermanos separados y nuestra fe aparecerá entre ellos más claramente expresada» ${ }^{138}$. Y, con las mismas coordenadas que el Decreto Unitatis redintegratio, el editorial sostiene que la dificultad de las relaciones ecuménicas reside en la recíproca ignorancia ${ }^{139}$, y aboga por el conocimiento mutuo de los miembros de diferentes denominaciones cristianas:

«Hasta ahora, el gran obstáculo entre protestantes y católicos era el mutuo desconocimiento. Por tanto, lo primero que es urgente hacer es el acercamiento mutuo, único camino para derribar prejuicios, para fomentar la fraternidad y trabajar juntos a partir de ello. El proselitismo desconsiderado de algunas denominaciones (por supuesto no hablamos de 'sectas' que nada o muy poco tienen que ver con el cristianismo) tantas veces basado en la tremenda ignorancia de amplios sectores católicos, puede muy bien compaginarse con la desconsiderada actitud de muchos católicos para los que 'ser protestante' es algo así como 'ser hijos del Diablo'. Entre nosotros, la respetuosa denominación de 'hermanos separados' no ha pasado de ser un irónico eufemismo sin contenido. Lo cual es muy grave» ${ }^{140}$.

Por otro lado, es casi inexistente la presencia del Diálogo interreligioso $(1,1 \%)$ en los editoriales de Vida Nueva. Sin embargo, la revista es consciente de la importancia del tema y, parafraseando la Declaración Nostra aetate ${ }^{141}$, alude al objetivo cristiano "de anunciar constantemente a Cristo, pero también de no rechazar nada de lo que en estas religiones hay de santo y verdadero, de respetar sus modos de obrar y de vivir, sus preceptos y doctrinas de ver en ellas un destello de aquella verdad que ilumina a todos los hombres» ${ }^{142}$.

138 Editorial. "Protestantes y católicos en España”. Vida Nueva 888 (23 de junio de 1973): 5 .

139 Cf. UR 9.

140 Editorial. "Protestantes y católicos", 5.

141 NA 2.

142 Editorial. "El oriente visita a los cristianos". Vida Nueva 901 (6 de octubre de 1973): 5. 


\section{CONCLUSIONES}

Vida Nueva es una revista que acoge el Concilio Vaticano II en su misión y quehacer periodístico en el periodo posconciliar. El espíritu de las constituciones, decretos y declaraciones está presente en la línea temática eclesial de sus editoriales. En consecuencia, el mensaje conciliar influye en su manera de concebir la Iglesia y su forma de asimilar el proceso de renovación. Vida Nueva entiende su razón de ser desde el servicio a la Iglesia, estando en el mundo y para el mundo, considerándose a sí misma como una publicación independiente, cristiana, tradicional y conciliar antes del Concilio Vaticano II: conciliar, ya que advierte la necesidad de la renovación de la Iglesia; y tradicional, al proyectar una renovación moderada y paulatina orientada al regreso de las raíces evangélicas. A continuación, se exponen conclusiones más específicas de carácter eclesial que el semanario desarrolla en sus editoriales:

- La revista pone de relieve el camino de la Iglesia universal y de la Iglesia en España, dando voz a los acontecimientos eclesiales más destacados. Asimismo, a través del tratamiento del papa y de los obispos, el semanario muestra su afecto a la jerarquía de la Iglesia y mantiene a veces una postura crítica, sobre todo con las ideas o iniciativas eclesiales contrarias a la renovación. Igualmente, para Vida Nueva, la colegialidad episcopal tiene una función importante para la transformación de la Iglesia en el posconcilio.

- El semanario identifica una profunda crisis en el sacerdocio y en la vida religiosa, y fomenta la renovación de estos ministerios, especialmente, en el proceso de formación. En relación con el celibato, la revista expresa su comunión con la Encíclica Sacerdotalis caelibatus de Pablo VI, aunque también se muestra comprensiva con las propuestas del episcopado holandés sobre su opcionalidad. Sobre la admisión de la mujer a los ministerios, el semanario considera que hay asuntos más prioritarios, como la igualdad de sexos y el papel de la mujer en la Iglesia. Asimismo, se posiciona en contra de reducir la Iglesia a la jerarquía y propone una participación más activa de los laicos en los distintos órganos eclesiales.

- Vida Nueva aprecia como un signo de los tiempos el pluralismo eclesial y el espíritu renovador prevalente en la fase posconciliar. La revista, mostrando su sentido de pertenencia eclesial y haciendo 
presente el magisterio en los editoriales, se preocupa por la aplicación del Concilio Vaticano II y critica a quienes dentro de la Iglesia mantienen posturas preconciliares. Además, el semanario aboga por el impulso de la renovación en el campo de la teología, la liturgia, el lenguaje eclesial, la metodología pastoral y la devoción mariana.

- La evangelización también es un aspecto esencial de la renovación, ya que, para la revista, la misión de la Iglesia ha de ser llevada a cabo a través de la transmisión de la fe. Del mismo modo, Vida Nueva entiende el anuncio del evangelio acompañado del compromiso cristiano con las realidades temporales, considerando clave la defensa de los derechos humanos, la justicia social y la opción preferencial por los excluidos. El semanario se preocupa por el proceso gradual de secularización y ateísmo en Europa, y plantea una experiencia de fe más auténtica.

- Vida Nueva cubre los asuntos de naturaleza social del ámbito nacional e internacional en sus editoriales y hace referencia a documentos de la doctrina social de la Iglesia que considera fundamentales para la implicación de los cristianos en las realidades temporales. Están particularmente presentes la Constitución Gadium et Spes y las cartas encíclicas Rerum novarum, Pacem in terris y Populorum Progressio, subrayando las cuestiones relativas a la exclusión, los derechos humanos, la libertad, la paz y la justicia social.

- La revista fomenta un cambio de mentalidad y un espíritu de comunión con el resto de las confesiones cristianas, y celebra que organizaciones e iniciativas eclesiales aviven la tarea ecuménica. Aunque el diálogo interreligioso esté escasamente presente en los editoriales, el semanario aboga por el respeto y reconocimiento de otras religiones.

Vida Nueva no solo reflexiona y realiza propuestas en el campo eclesial. A la luz de la doctrina social de la Iglesia, los editoriales del semanario también tienen un papel crítico con la sociedad, poniendo especial atención en las necesidades de los excluidos y respondiendo a las problemáticas de un periodo marcado por la revolución cultural de 1968 y el tardofranquismo. Por ello, para conocer la línea editorial de la revista de manera integral, también es preciso profundizar en su pensamiento social, que será presentando en futuros estudios. 


\section{BIBLIOGRAFÍA}

FUENTES PRIMARIAS

Editorial. "José Luis Martín Descalzo sucede a José María Pérez Lozano en la dirección de Vida Nueva". Vida Nueva 650 (2 de noviembre de 1968): 5.

Editorial. "Creemos en el Vaticano II". Vida Nueva 655 (7 de diciembre de 1968): 5.

Editorial. "El escándalo de las separaciones". Vida Nueva 661 (18 de enero de 1969): 5.

Editorial. "Nuestros alféreces provisionales de la teología". Vida Nueva 662 (25 de enero de 1969): 5.

Editorial. “No siempre 'entusiasmo' es 'vocación”'. Vida Nueva 665 (15 de febrero de 1969): 5.

Editorial. "La encíclica traspapelada". Vida Nueva 670 (22 de marzo de 1969): 5.

Editorial. "134 maneras de ser católico". Vida Nueva 675/676 (26 de abril/3 mayo de 1969): 3 .

Editorial. "El viaje del 'mariscal"'. Vida Nueva 681 (7 de junio de 1969): 5.

Editorial. "Un tiempo apasionante”. Vida Nueva 697 (27 de septiembre de 1969): 5.

Editorial. "Encaje de bolillos". Vida Nueva 708 (13 de diciembre de 1969): 5.

Editorial. "Sacerdotes secularizados". Vida Nueva 712 (10 de enero de 1970): 20.

Editorial. "La idolatría de los medios". Vida Nueva 713 (17 de enero de 1970): 5.

Editorial. "Holanda: no un cisma, pero sí un conflicto". Vida Nueva 715 (31 de enero de 1970): 5.

Editorial. "Un orden de factores que sí altera el producto". Vida Nueva 717 (14 de febrero de 1970): 5.

Editorial. "Toda da la verdad sobre los sacerdotes". Vida Nueva 722 (21 de marzo de 1970): 3.

Editorial. "Las cuatro caras de una fecha". Vida Nueva 727 (26 de abril de 1970): 5.

Editorial. “Década del 70: ¿Qué esperan los seglares?”. Vida Nueva 729 (9 de mayo de 1970): 5. 
Editorial. "Breves notas para una conclusión”. Vida Nueva 730 (17 de mayo de 1970): 31.

Editorial. "Las cuatro caras de una fecha". Vida Nueva 727 (26 de abril de 1970): 5.

Editorial. "Pablo VI, un difícil y exaltante destino". Vida Nueva 731 (23 de mayo de 1970): 5.

Editorial. "Nuestra Iglesia de los pobres". Vida Nueva 734/735 (13/20 de junio de 1970): 3-4.

Editorial. "Los seglares también son diócesis". Vida Nueva 736 (27 de junio de 1970): 5 .

Editorial. "Obstat sexus". Vida Nueva 750 (3 de octubre de 1970): 3.

Editorial. "No son un dilema”. Vida Nueva 751 (10 de octubre de 1970): 3.

Editorial. "La Iglesia, que Dios ha unido... no la desunamos los cristianos". Vida Nueva 766 (23 de enero de 1971): 5.

Editorial. "Una moral sin raíces". Vida Nueva 768 (30 de enero de 1971): 5.

Editorial. "Las monjas: 'del cero al infinito'”. Vida Nueva 772 (6 de marzo de 1971): 5.

Editorial. “Seminarios, ¿vacíos?”. Vida Nueva 774 (20 de marzo de 1971) p. 5.

Editorial. "La Pascua, otra vez". Vida Nueva 778 (17 de abril de 1971): 5.

Editorial. "Una Iglesia políticamente libre". Vida Nueva 780 (1 de mayo de 1971): 5.

Editorial. "La carta de Pablo VI... El cristal con que se mira". Vida Nueva 783 (22 de mayo de 1971): 5.

Editorial. "A la dulce piedad de Dios". Vida Nueva 785 (5 de junio de 1971): 5.

Editorial. "Un nuevo mensaje de Pablo VI a España". Vida Nueva 793 (31 de julio de 1971): 5 .

Editorial. "Un paso histórico en la vida de nuestra Iglesia". Vida Nueva 799/800 (25 de septiembre/2 de octubre de 1971): 3-5.

Editorial. “La mujer ¿tema candente?”. Vida Nueva 803 (23 de octubre de 1971): 5.

Editorial. "Hora de trabajar unidos". Vida Nueva 817 (29 de enero de 1972): 5.

Editorial. "Frente a toda esclavitud". Vida Nueva 820 (19 de febrero de 1972): 5.

Editorial. “El Dios de los franceses". Vida Nueva 829 (22 de abril de 1972): 5. 
Editorial. "Cuatro palabras del Papa". Vida Nueva 836 (10 de junio de 1972): 5.

Editorial. "Verano caliente". Vida Nueva 838 (24 de junio de 1972): 5.

Editorial. "Setenta y cinco años". Vida Nueva 849 (23 de septiembre de 1972): 5.

Editorial. "La herencia de Juan XXIII". Vida Nueva 852 (14 de octubre de 1972): 5.

Editorial. "La reforma del Cónclave. Más difícil de lo que parece". Vida Nueva 873 (10 de marzo de 1973): 5.

Editorial. "Diez años de la Pacem in terris... Y la paz (la verdadera) no vino". Vida Nueva 879 (21 de abril de 1973): 5.

Editorial. “18.000 jóvenes celebran la Pascua”. Vida Nueva 880 (28 de abril de 1973): 5.

Editorial. "Protestantes y católicos en España". Vida Nueva 888 (23 de junio de 1973): 5.

Editorial. "Con cariño y sin idolatría". Vida Nueva 889 (30 de junio de 1973): 5.

Editorial. "El riesgo de evangelizar". Vida Nueva 893 (28 de julio de 1973): 5.

Editorial. "Veinticinco años del Consejo Ecuménico de Iglesias". Vida Nueva 896 (1 de septiembre de 1973): 5.

Editorial. "El oriente visita a los cristianos". Vida Nueva 901 (6 de octubre de 1973): 5 .

Editorial. "Actores y espectadores". Vida Nueva 902 (13 de octubre de 1973): 5.

Editorial. "No es un asunto de chinitos". Vida Nueva 903 (20 de octubre de 1973.): 5.

Editorial. "Diócesis conflictivas". Vida Nueva 904 (27 de octubre de 1973): 45.

Editorial. "María del siglo XX”. Vida Nueva 926 (30 de marzo de 1974): 5.

Editorial. "Prefiero una religión sin sacerdotes...". Vida Nueva 936 (8 de junio de 1974): 5.

Editorial. "La esperanza joven de Taizé". Vida Nueva 946 (31 de agosto/8 de septiembre de 1974): 5.

Editorial. "Navidades sin Cristo". Vida Nueva 961 (21 de diciembre de 1974): 5.

Editorial. "La cuarta singladura de la Conferencia episcopal española". Vida Nueva 971 (1 de marzo de 1975): 5-7.

Editorial. "El cura incómodo". Vida Nueva 973, (15 de marzo de 1975): 5. 
Editorial. "Pablo VI y los jesuitas". Vida Nueva 974 (22 de marzo de 1975): 5. Editorial. “Điez años ya, Dios Santo!”. Vida Nueva 1008 (13 de diciembre de 1975): 5.

Editorial. "Año nuevo, director nuevo". Vida Nueva 1011 (3 de enero de 1976): 5.

Martín Descalzo, José Luis. "Qué ha sido, qué es, qué quiere ser Vida Nueva". Vida Nueva 1000 (11/18 de octubre de 1975): 7.

Martín Descalzo, José Luis, y Bernardino Martínez Hernando. "3.600 lectores de Vida Nueva juzgan su revista".

Vida Nueva 602 (2 de diciembre de 1967).

Vida Nueva 1009 (20 de diciembre de 1975): 22-31.

Vida Nueva 1010 (27 de diciembre de 1975): 3.

FuENTES SECUNDARIAS

Alberigo, Giuseppe. Historia del Concilio Vaticano II. Vol. III. Salamanca: Sígueme/Peeters, 2006.

Barrera, Carlos. "Revistas católicas y conflictos con el poder político en el tardofranquismo". Anuario de la Historia de la Iglesia 10 (2001): 101-142.

Berganza Conde, María Rosa. "La aplicación de métodos estadísticos a la investigación en medios de comunicación". En Investigar en Comunicación. Guía práctica de métodos y técnicas de investigación social en Comunicación, dirigido por María Rosa Berganza Conde y José Antonio Ruiz San Román, 113-147. Madrid: McGraw-Hill, 2005.

Cagigas Ocejo, Yolanda. La revista Vida Nueva (1967-1976): un proyecto de renovación en tiempos de crisis. Pamplona: EUNSA, 2007.

Concilio Vaticano II. "Documentos del Concilio Vaticano II". La Santa Sede. 1966. Consultado el 27 de diciembre de 2019. http://www.vatican. va/archive/hist_councils/ii_vatican_council/index_sp.htm

Conferencia Episcopal Española. "La Iglesia y los pobres". 11 de julio de 1970. Consultado el 27 de diciembre de 2019. http://www.conferenciaepiscopal.nom.es/archivodoc/jsp/system/win_main.jsp

Conferencia Episcopal Española. La Iglesia y la comunidad política: documentos de la XVII Asamblea Plenaria del Episcopado Español. Madrid: PPC, 1973.

Conferencia Episcopal Española. "La Iglesia ante el momento actual: petición de libertad para detenidos políticos. 19 de diciembre de 1975. 
Consultado el 27 de diciembre de 2019. http://www.conferenciaepiscopal.nom.es/archivodoc/jsp/system/win_main.jsp

García Galera, María del Carmen, y María Rosa Berganza Conde. "El método científico aplicado a la investigación en Comunicación Mediática". En Investigar en Comunicación. Guía práctica de métodos y técnicas de investigación social en Comunicación, dirigido por María Rosa Berganza Conde y José Antonio Ruiz San Román,19-42. Madrid: McGraw-Hill, 2005.

González de Cardedal, Olegario. La Teología en España (1959-2009). Memoria y prospectiva. Madrid: Encuentro, 2010.

Juan XXIII. “Carta Encíclica Pacem in Terris”. La Santa Sede. 11 de abril de 1963. Consultado el 23 de diciembre de 2019. http://www.vatican.va/ content/john-xxiii/es/encyclicals/documents/hf_j-xxiii_enc_11041963_ pacem.html

Laboa, Juan María. Pablo VI, España y el Concilio Vaticano II. Madrid: PPC, 2017.

Legorreta Zepeda, José de Jesús. "Las conferencias episcopales en el debate teológico postconciliar". Revista Iberoamericana de Teología 13 (2011): 31-55.

León XIII. "Carta Encíclica Rerum novarum”. La Santa Sede. 5 de mayo de 1891. Consultado el 23 de diciembre de 2019. http://www.vatican. $\mathrm{va} /$ content/leo-xiii/es/encyclicals/documents/hf_l-xiii_enc_15051891_ rerum-novarum.html

Madrigal, Santiago. "La recepción del Concilio Vaticano II". Revista Iberoamericana de Teología 13 (2011): 57-90.

Madrigal, Santiago. "El Concilio Vaticano II: remembranza y actualización". Revista Teología 117 (2015): 131-163.

Martín de Santa Olalla, Pablo, y José Francisco Serrano Oceja. 50 años de la Conferencia Episcopal Española. Madrid: Encuentro, 2016.

Martínez Hernando, Bernardino. "Historia de Vida Nueva. Los últimos 30 años del catolicismo español a través de una revista". Tesina de fin de carrera en la Escuela Oficial de Periodismo, Madrid, 1973.

Martínez Hernando, Bernardino. "La personalidad de Vida Nueva. Análisis hemerográfico". Tesina de Licenciatura, Facultad de Ciencias de la Información, Universidad Complutense de Madrid, 1982.

Martínez Hernando, Bernardino. Comunicación con el autor, 17 de octubre de 2017.

McCombs, Maxwell E., y Donald L. Shaw. "The Agenda-Setting Function of Mass Media". The Public Opinion Quarterly 36, n. ${ }^{\circ} 2$ (1972): 176-187. 
Orbegozo, Ángel. La Prensa de la Iglesia en España. Madrid: Oficina General de Información y Estadística de la Iglesia en España, 1957. Ortega, Joaquín Luis. Comunicación con el autor, 19 de noviembre de 2017.

Pablo VI. "Carta Encíclica Populorum Progressio". La Santa Sede. 26 de marzo de 1967. Consultado el 23 de diciembre de 2019. http:// www.vatican.va/content/paul-vi/es/encyclicals/documents/hf_p-vi_ enc_26031967_populorum.html

Pablo VI. "Encíclica Sacerdotalis Caelibatus". La Santa Sede. 24 de junio de 1967. Consultado el 23 de diciembre de 2019. http://www.vatican. va/content/paul-vi/es/encyclicals/documents/hf_p-vi_enc_24061967_ sacerdotalis.html

Pablo VI. "Carta Apostólica Octogesima adveniens". La Santa Sede. 14 de mayo de 1971. Consultado el 23 de diciembre de 2019. http:// w2.vatican.va/content/paul-vi/es/apost_letters/documents/hf_p-vi_ apl_19710514_octogesima-adveniens.html

Pablo VI. "Exhortación Apostólica Marialis Cultus". La Santa Sede. 2 de febrero de 1974. Consultado el 23 de diciembre de 2019. http:// www.vatican.va/content/paul-vi/es/apost_exhortations/documents/ hf_p-vi_exh_19740202_marialis-cultus.html

Pelayo, Antonio. Comunicación con el autor, 7 de abril de 2014.

Sánchez-Camacho, Jesús. "El impacto del Concilio Vaticano II y la transformación social de la España tardofranquista en la línea editorial de Vida Nueva (1968-1975)". Tesis doctoral, Universidad Pontificia de Salamanca, 2018.

Santamaría, Luisa. El comentario periodístico. Los géneros persuasivos. Madrid: Paraninfo, 1990.

Serrano Oceja, José Francisco. "La obra publicística de Lamberto de Echeverría y Martínez de Marigorta: Incunable y PPC en la renovación del catolicismo español”. Tesis doctoral, Universidad Pontificia de Salamanca, 1999.

Tusell, Javier. La España de Franco. Madrid: Historia 16, 1989.

Vida Nueva 1010 (27 de diciembre de 1975): 3.

Wallace Platt, Philip. Gentle Eminence. A life of Cardinal Flahiff. Québec: McGill-Queen's University Press, 1999.

Watt, Ninfa. "Vida Nueva. Medio Siglo de una revista (1985-2008)". Tesis doctoral, Universidad Pontificia de Salamanca, 2008. 
Watt, Ninfa, Pablo Rey, y José David Urchaga-Litago. Vida Nueva en la Transición. Iglesia y sociedad españolas en la línea editorial del semanario de PPC. Barcelona: Ediciones STJ, 2010.

Wimmer, Roger, y Joseph Dominick. La investigación científica de los medios de comunicación. Barcelona: Bosch Casa Editorial S.A., 1996.

Zammit, Mark Joseph. "«La Iglesia se inclina hacia el hombre y hacia el mundo»: el puesto central del diálogo de Pablo VI en el Concilio Vaticano II". Estudios Eclesiásticos 370 (2019): 513-556. DOI: https://doi. org/10.14422/ee.v94.i370.y2019.003 